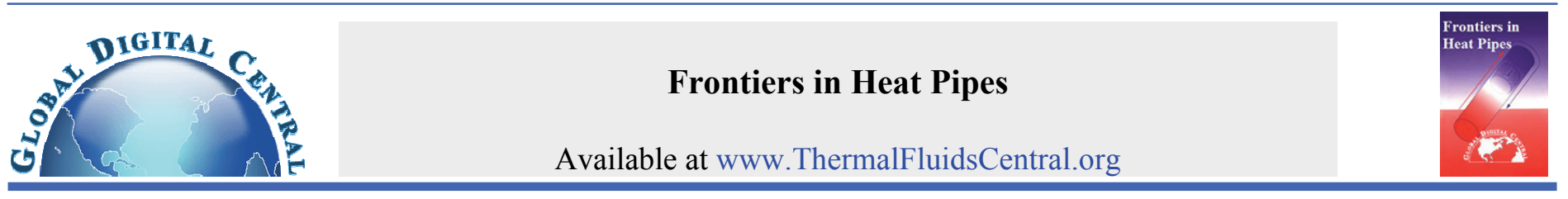

\title{
VISUALIZATION EXPERIMENT ON THE EVAPORATION CHARACTERISTICS IN NANOPARTICLE-LADEN MESH-WICKED HEAT PIPES
}

\author{
Shwin-Chung Wong*, Ya-Chi Ho \\ Department of Power Mechanical Engineering, National Tsing Hua University, Taiwan, ROC
}

\begin{abstract}
Visualization experiments are conducted on horizontal heat pipes to investigate the effects of $\mathrm{Al}_{2} \mathrm{O}_{3}$ or $\mathrm{Cu}$ nanoparticles laden in mesh-wick evaporator. The nanoparticle-laden evaporator appears quiescent with no sign of boiling. With $0.01 \mathrm{~g} \mathrm{Cu}$ nanoparticles sintered in the evaporator, the maximum heat load $Q_{\max }$ and the minimum evaporator resistance $R_{\mathrm{e}, \min }$ are only slightly improved. With $0.01 \mathrm{~g}$ or $0.04 \mathrm{~g}$ sedimented $\mathrm{Al}_{2} \mathrm{O}_{3}$ nanoparticles, $R_{\mathrm{e}, \min }$ reduces by $20 \%$. $Q_{\max }$ increases by $20 \%$ with a larger amount of $\mathrm{Al}_{2} \mathrm{O}_{3}$ nanoparticles. $R_{\mathrm{e}, \min }$ improvement may be attributed to additional heat paths with numerous micro menisci for thin-film evaporation. $Q_{\max }$ increases with enhanced capillarity by nanoparticle agglomerates.

Keywords: Heat pipe, mesh wick, nanofluids, nanoparticles, evaporator resistance
\end{abstract}

\section{INTRODUCTION}

Nanofluids have received tremendous attention because they have considerably enlarged thermal conductivities (Keblinski, et al., 2002). They have been adopted as the working fluid of mesh-wicked heat pipes (Tsai et al., 2004; Do et al., 2010; Liu and Zhu, 2011; Putra et al., 2012), grooved heat pipes (Kang et al., 2006; Liu and Lu, 2009; Yang et al., 2008), sintered-powder heat pipes (Kang et al., 2009). A number of recent review papers have been available (Liu and Li, 2012; Kumaresan and Venkatachalapathy, 2012; Sureshkumar et al., 2013). All these studies reported significant performance enhancement. However, the mechanism for such improvements has not been well understood. While it has been attributed to the enlarged conductivity in some studies (Kang et al., 2006; Liu and Lu, 2009; Yang et al., 2008; Kang et al., 2009), a different view suggested that the thin porous layer formed by sedimented nanoparticles, which increases the surface wettability and capillarity in the evaporator wick, may play a primary role (Do et al., 2010). Unlike pulsating heat pipes in which strong oscillating motions keep the nanoparticles suspended during operation (Ma et al., 2006; Lin et al., 2008), the nanoparticles in regular heat pipes tend to sediment into a thin porous layer. Especially for meshwicked and sintered-powder heat pipes, it is expected that the sedimented nanoparticles would agglomerate and become trapped and immobile in the wicks. On the other hand, nanoparticles have been found to improve the pool boiling performance over a grooved surface (Liu et al., 2007) and a flat surface (Kwark et al., 2010) under certain conditions. Direct visualization of the evaporation characteristics in the nanoparticle-laden evaporator of operating heat pipes can be helpful in identifying the mechanism for performance enhancement. In the present study, we will apply our technique of visualization experiment on operating heat pipes (Liou et al., 2010; Wong et al., 2010; Wong et al., 2012) to nanoparticles-laden evaporators.

\section{EXPERIMENTAL METHODS}

The experimental methods follow our recent works (Liou et al., 2010; Wong et al., 2010; Wong et al., 2012). A detailed description of the heat pipe structure and experimental procedure is available in Ref. (Liou et al., 2010). Here is given a brief description. Fig. 1 shows the overall test setup. The $22 \mathrm{~mm} \times 11 \mathrm{~mm}$ heated surface of the heat pipe is connected to the uniform-temperature top surface $(20 \mathrm{~mm} \times 10 \mathrm{~mm})$ of a heating post via a layer of thermal grease. The $22 \mathrm{~mm}$ width of the heated area is near the $25 \mathrm{~mm}$ width of the wick, making the thermal distribution of the heat pipe approximately one-dimensional. A cut-off trench, leaving a plate thickness of $1 \mathrm{~mm}$, is made around the heated area and across the plate width (cf. Fig. 2) to reduce lateral conduction through the base plate. The heating post is carefully insulated except at its top end. The bottom of the other end of the heat pipe is cooled by a cold plate with running water at $20{ }^{\circ} \mathrm{C}$. Except for these heated and cooled regions, the heat pipe is well insulated during operation. To prevent condensation on the visualization window, the insulation material over the window is removed shortly for recording only. A CCD camera equipped with a microscopic lens (Optem, Zoom 125) shoots vertically downward through the observation window. High magnification of the evaporation zone can be obtained. Illumination is provided by high-intensity LED lights.

Figure 2 shows the flat-plate heat pipe designed for visualization and thermal resistance measurement, along with the positions of seven implanted thermocouples. These thermocouples, K-type $1 \mathrm{~mm}$-diameter stainless-steel sheathed probe (Omega, Inc.), are denoted by $\mathrm{T} 1$ to T7, respectively. Thermocouple signals are recorded by a data logger (Fluke, Hydra Series II) with a resolution of 0.1 . T1 and T2 are used to calculate the total heat load $Q_{\mathrm{t}}$ through the copper heating post. T3 measures in the middle of the copper plate at the center of the heated area. Suspended about $1 \mathrm{~mm}$ above the center of the evaporator, T4

\footnotetext{
* Corresponding author. Email: scwong@pme.nthu.edu.tw
} 
measures the vapor temperature leaving the evaporator. T5-T6 are managed to evaluate the lateral conduction through the copper plate (Liou et al., 2010), $Q_{\text {cond, }}$ as will be discussed later. T7 measures the copper plate temperature in the cooled area.

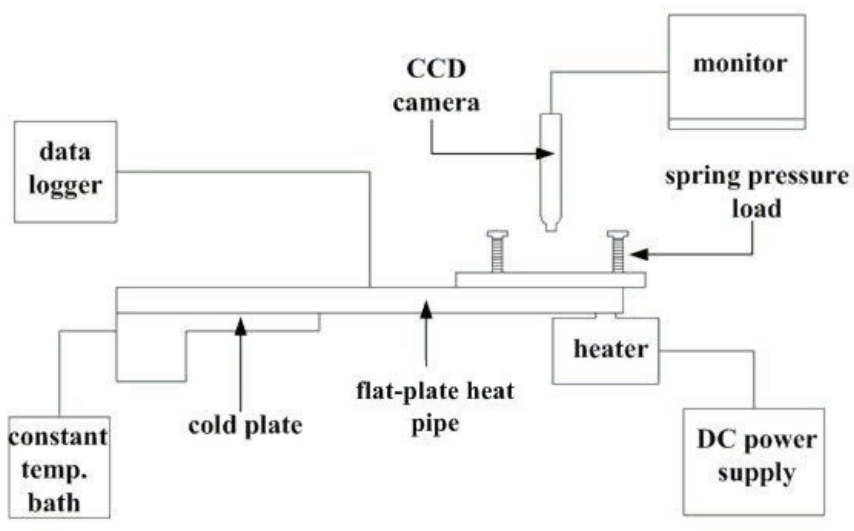

Fig. 1 Overall experimental setup.

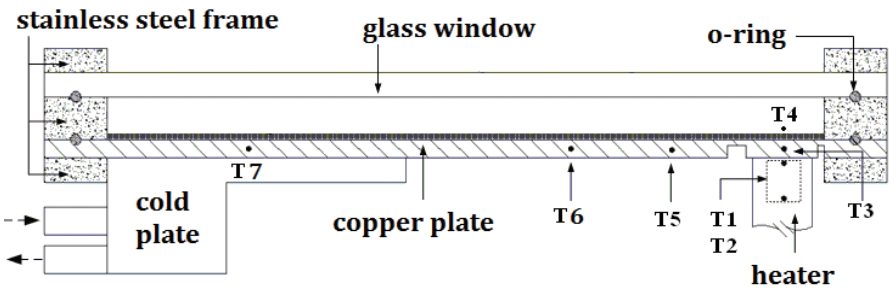

Fig. 2 The flat-plate heat pipe along with thermocouple positions.

The $100+200$ mesh wick, with an upper 100 mesh and a lower 200 mesh woven screen, is sintered on a $4 \mathrm{~mm}$ thick C1020 oxygenless copper base plate under a fixed pressure in a $800{ }^{\circ} \mathrm{C}$ hydrogen/nitrogen atmosphere for $2 \mathrm{~h}$. To accommodate the wick, a region of $117 \times 25$ $\mathrm{mm}^{2}$ on the upper surface of the base plate is cut lower by a depth of 1 $\mathrm{mm}$. This is done to prevent the possibility that a small amount of the working liquid may cycle back via the narrow path between the o-ring and the copper plate, rather than through the wick. Before sintering, the screens and the copper plate are carefully cleaned. The heat pipe has a top glass window for observation. The internal space of the heat pipe is $120 \times 30 \times 7 \mathrm{~mm}^{3}$. With the contact surfaces between different pieces sealed with o-rings, the whole structure, including the wicked copper base plate, the top glass window, and the stainless-steel frames, is tightened with bolts. It is noted that excess charge is needed in the present experiments to compensate for the liquid accumulation at the corners, gaps and walls in the heat pipe. A fixed amount of $0.8 \mathrm{~cm}^{3}$ (the saturate charge is $0.5 \mathrm{~cm}^{3}$ ) of degassed de-ionized water or nanofluid is filled into the heat pipe right after it is evacuated down to a pressure of $1 \times 10^{-2}$ Torr. The heat load is increased stepwise from a low heat load, and data are taken under a thermally stable condition for each heat load.

Usually, the capillarity of the sintered copper wick degrades in air with time due to surface oxidation. In this work, the copper surface wettability is quantified by the contact angle of a sessile water drop on a smooth surface. The contact angle is measured on another plate, which has been taken out of the sintering oven simultaneously with the wicked copper plate, when the heat pipe is evacuated to 1 Torr. For all the tests, the static contact angles of water on a smooth copper surface are controlled at $10^{\circ}-12^{\circ}$.

The evaporator resistance $R_{\mathrm{e}}$ is determined as

$R_{\mathrm{e}}=(\mathrm{T} 3-\mathrm{T} 4) / Q$, where $Q=Q_{\mathrm{t}}-Q_{\text {cond }}$. The net heat flux $q=Q / A_{\mathrm{e}}$, with the heated area $A_{\mathrm{e}}=2.42 \mathrm{~cm}^{2}$. In this study, the ratios of $Q_{\text {cond }} / Q_{\mathrm{t}}$ prior to the occurrence of local dryout are about $1.1-3 \%$, smaller for a smaller evaporator resistance. The uncertainty in the measurements of $Q$ is $7 \%$. This is determined by comparing the output of the DC power supply and the estimated value based on the temperature difference (T1 - T2). The uncertainty in $R_{\mathrm{e}}$ values is also $7 \%$, since the uncertainties primarily arose from those of $Q$, according to the definition of $R_{\mathrm{e}}$ in Eq. (1).

Two kinds of nanoparticles, $\mathrm{Al}_{2} \mathrm{O}_{3}$ and $\mathrm{Cu}$, are laden in the evaporator wick. The $\mathrm{Al}_{2} \mathrm{O}_{3}$ nanoparticles are a commercial product with a monodisperse size of about $50 \mathrm{~nm}$. The $\mathrm{Cu}$ nanoparticles, smaller than $100 \mathrm{~nm}$, have been chemically made from $\mathrm{Cu}\left(\mathrm{NO}_{3}\right)_{2}$ in our lab. The two kinds of nanoparticles are laden into the evaporator in different manners. The $\mathrm{Al}_{2} \mathrm{O}_{3}$ nanoparticles are well blended in de-ionized water using an ultrasonic blender to form a nanofluid without surfactant. The nanofluid is then filled into the evacuated heat pipe. The $\mathrm{Cu}$ nanoparticles are weakly sintered within the wick in a $575{ }^{\circ} \mathrm{C}$ hydrogen/nitrogen atmosphere for $0.5 \mathrm{~h}$ before water filling. The mass of $\mathrm{Cu}$ nanoparticles sintered in the wick is 0.01 g. Fig. 3 shows an SEM image of $\mathrm{Cu}$ nanoparticles on a flat copper plate under the same sintering condition. The $\mathrm{Cu}$ nanoparticles can be seen to partially bonded into numerous large porous agglomerates. Fig. 4 shows a magnified image of a dried $100+200$ mesh wick with $\mathrm{Al}_{2} \mathrm{O}_{3}$ nanoparticles dried after the filling. The $\mathrm{Al}_{2} \mathrm{O}_{3}$ nanoparticles distribute non-uniformly with large agglomerates due to inter-particle adhesion. With a fluid charge of $0.8 \mathrm{~cm}^{3}$, the fraction of the $\mathrm{Cu}$ nanoparticles is $1.25 \mathrm{wt} \%$ (or $0.14 \mathrm{vol} \%$ ). However, because all $\mathrm{Cu}$ nanoparticles are located in the evaporator, such concentration values are not to be directly compared with the concentrations of nanofluids for which the nanoparticles may be distributed over the heat pipe. The amount of $\mathrm{Al}_{2} \mathrm{O}_{3}$ nanoparticles charged into the heat pipe is $0.01 \mathrm{~g}$ or $0.04 \mathrm{~g}$. The fraction of the $\mathrm{Al}_{2} \mathrm{O}_{3}$ nanoparticles are $1.25 \mathrm{wt} \%$ (or $0.31 \mathrm{vol} \%$ ) and $5 \mathrm{wt} \%$ (or $1.25 \mathrm{vol} \%$ ), respectively. During liquid filling, the heat pipe is vertically placed with the evaporator at the bottom. Thus, the $\mathrm{Al}_{2} \mathrm{O}_{3}$ nanoparticles may be distributed over the heat pipe but somewhat denser at the evaporator.

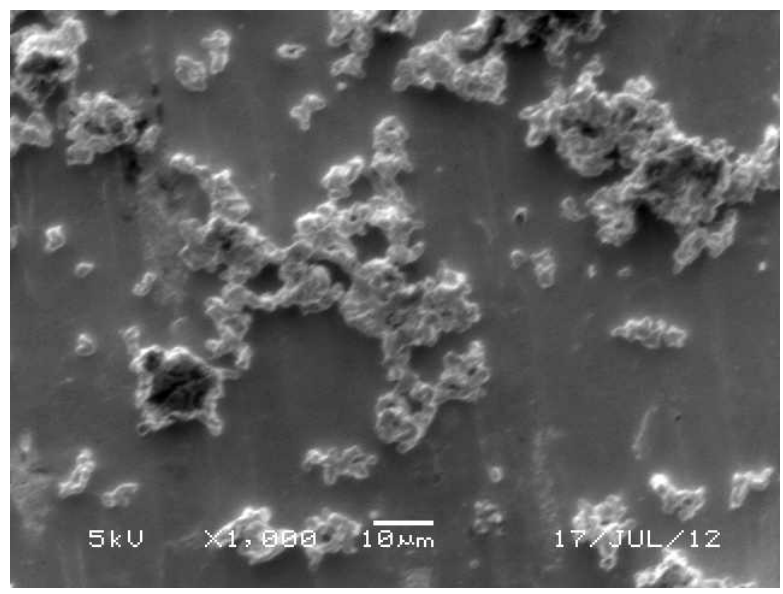

Fig. $3 \mathrm{Cu}$ nanoparticles sintered on a copper plate.

\section{RESULTS AND DISCUSSION}

Experiments were conducted for four different test cases with the $100+200$ mesh wick and a fixed liquid charge of $v=0.8 \mathrm{~cm}^{3}:$ (1) pure water without nanoparticles, (2) water with $0.01 \mathrm{~g} \mathrm{Cu}$ nanoparticles sintered in the evaporator, (2) water with $0.01 \mathrm{~g} \mathrm{Al}_{2} \mathrm{O}_{3}$ nanoparticles, and (4) water with $0.04 \mathrm{~g} \mathrm{Al}_{2} \mathrm{O}_{3}$ nanoparticles. Visualization was made for the evaporation process and the evaporator resistances were measured versus heat load until local dryout occurred in the evaporator. 


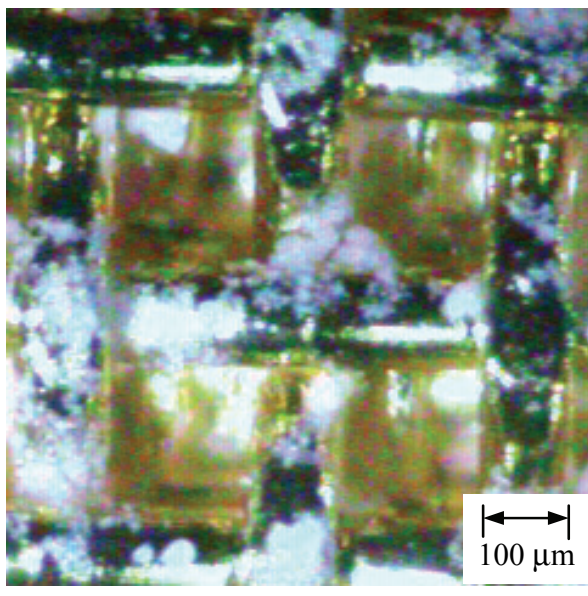

Fig. $4 \mathrm{Al}_{2} \mathrm{O}_{3}$ nanoparticles in a dry $100+200$ mesh wick.

\subsection{Visualization Results}

For all these cases, the evaporator appears quiescent during operation with no sign of nucleate boiling. The water layer in the evaporator becomes thinner with the increase of heat load. In response to the thinning water layer, the evaporator resistance gradually decreases to a minimum value, $R_{\mathrm{e}, \min }$, before it rises as a result of local dryout in the evaporator. Representatively, Fig. 5 compares the images near the center of the evaporator at $Q=0 \mathrm{~W}$ and $79.3 \mathrm{~W}$ for a test charged with pure water. At $Q=0 \mathrm{~W}$, the wick is mostly immersed in the liquid, with exposed peaks of the upper screen. At $Q=79.3 \mathrm{~W}$, when $R_{\mathrm{e}, \min }$ occurs, most of the upper 100 mesh screen has been exposed but the lower 200 mesh screen is still immersed. Under heat load, the thickness of the liquid layer in the evaporator decreases toward the evaporator end of the heat pipe because the supply of the condensed liquid is gradually consumed in the evaporator. At the condition with $R_{\mathrm{e}, \mathrm{min}}$, the liquid layer in the wick near the end-edge of the evaporator usually is hardly visible, as illustrated in Fig. 6 for the case with $0.01 \mathrm{~g} \mathrm{Al}_{2} \mathrm{O}_{3}$ nanoparticles at $Q=84.3 \mathrm{~W}$. The above characteristics are similar to our previous results for sintered multi-layer copper mesh wicks (Liou et al., 2010) and sintered irregular-powder wicks (Wong et al., 2010) using water as the working fluid. It is noted that nucleate boiling was not observed with a superheat as large as $13.7 \mathrm{~K}$ in our previous work (Wong et al., 2010). The present tests indicate that the nanoparticles laden in the evaporator fail to help activate nucleate boiling when the working fluid is water.

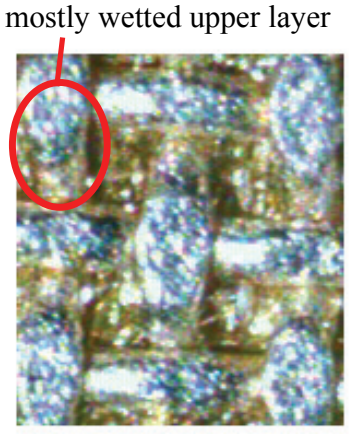

(a)

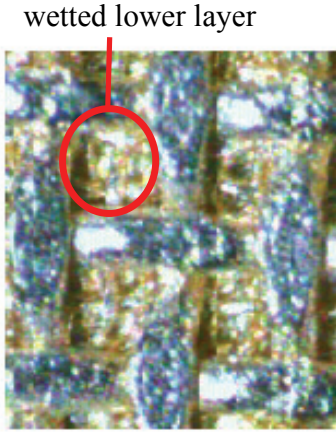

(b)
Fig. 5 Wetted 100+200 mesh evaporator with pure water, (a) at $Q=$ $0 \mathrm{~W}$; (b) at $Q=79.3 \mathrm{~W}$ with $R_{\mathrm{e}, \mathrm{min}}$.

Figure 7 presents the images at $Q_{\max }$, when $R_{\mathrm{e}, \min }$ occurs, near the evaporator center for three different cases. In Fig. 7a and $7 b$, the lower screen is immersed in water. In Fig. 7c for the case with $0.04 \mathrm{~g} \mathrm{Al}_{2} \mathrm{O}_{3}$ nanoparticles, the mesh wires of the lower 200 mesh screen are buried in the nanoparticle layer. The liquid seems absorbed in the thick porous nanoparticle layer, which will be shown to result in a larger $Q_{\max }$.

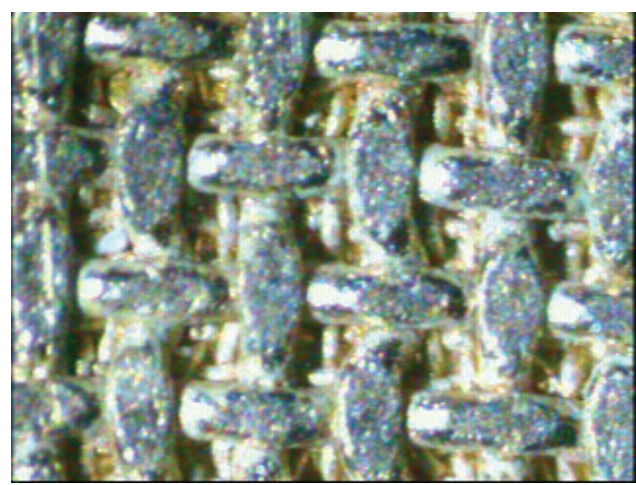

Fig. 6 Nearly dried wick at the evaporator end-edge when $R_{\mathrm{e}, \mathrm{min}}$ occurs for the case with $0.01 \mathrm{~g} \mathrm{Al}_{2} \mathrm{O}_{3}$ nanoparticles, $Q=84.3 \mathrm{~W}$.

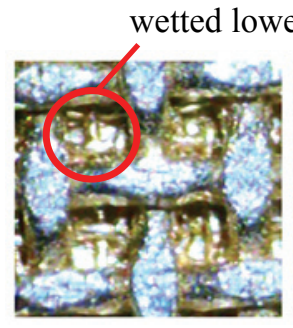

(a)

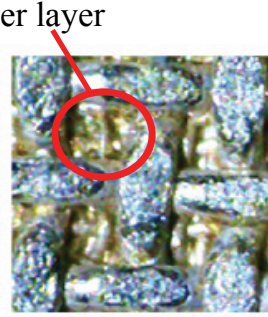

(b)

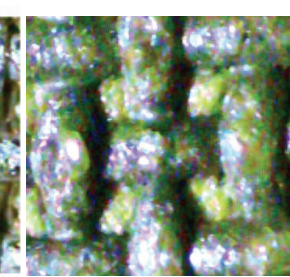

(c)
Fig. 7 Evaporator images at $R_{\mathrm{e}, \min }$, (a) water with $0.01 \mathrm{~g}$ sintered $\mathrm{Cu}$ nanoparticles, $Q_{\max }=81.0 \mathrm{~W}$; (b) water with $0.01 \mathrm{~g} \mathrm{Al}_{2} \mathrm{O}_{3}$ nanoparticles, $Q_{\max }=84.3 \mathrm{~W}$; (c) water with $0.04 \mathrm{~g} \mathrm{Al}_{2} \mathrm{O}_{3}$ nanoparticles, $Q_{\max }=93.9 \mathrm{~W}$.

\subsection{Evaporator Performance}

Figure 8 compares the evaporator resistances $R_{\mathrm{e}}$ versus heat load $Q$ for the four cases. As mentioned earlier, the present experimental technique has a drawback that a small amount of working liquid would be trapped on the inner corners, gaps, and wall of the chamber. According to our experience through tests without nanoparticles, this drawback, along with finite heat load increment, introduces disperse in $Q_{\max }$ of roughly $\pm 8 \%$, whereas $R_{\mathrm{e}, \min }$ is hardly influenced (Liou, et al., 2010; Wong et al., 2010; Wong et al., 2012). Similar to the characteristics observed in these tests, the evaporator resistances in the present cases reduce with increasing heat load until local dryout occurs. For the case with $0.01 \mathrm{~g}$ sintered $\mathrm{Cu}$ nanoparticles, although there is a slight increase in $Q_{\max }$, it is limited when the uncertainty associated with the present experimental technique is considered. Slight reduction in $R_{\mathrm{e}, \min }$ is shown. Since $R_{\mathrm{e}, \mathrm{min}}$ occurs when the liquid layer in the evaporator wick is thinner, the nanoparticles near the evaporator end where the liquid layer is thinnest can be exposed. In this situation, smaller $R_{\mathrm{e}, \text { min }}$ may be attributed to the increased thermal paths provided by the nanoparticles. On the numerous additional micro- and nano-scale menisci, thin-film evaporation occurs. Since the copper nanoparticles are sintered on the base plate, the thermal resistances through these new paths should be pretty low. As a result, a lower overall evaporator resistance $R_{\mathrm{e}, \min }$ is reached. For the case with $0.01 \mathrm{~g} \mathrm{Al}_{2} \mathrm{O}_{3}$ nanoparticles, the $R_{\mathrm{e}, \min }$ is reduced by $20 \%$, even more than the case with $0.01 \mathrm{~g}$ sintered $\mathrm{Cu}$ nanoparticles. The reason may be explained as follows. Both sintered $\mathrm{Cu}$ nanoparticles and sendimented $\mathrm{Al}_{2} \mathrm{O}_{3}$ nanoparticles can provide additional thermal paths for thin-film evaporation. Between the copper surfaces and the $\mathrm{Al}_{2} \mathrm{O}_{3}$ nanoparticles there exists contact resistance which introduces higher thermal resistance. However, the volume fraction of $\mathrm{Al}_{2} \mathrm{O}_{3}$ nanoparticles $(0.31 \mathrm{vol} \%)$ is larger than that of $\mathrm{Cu}$ 
nanoparticles $(0.14 \mathrm{vol} \%)$ due to the lower density of $\mathrm{Al}_{2} \mathrm{O}_{3}$. Besides, the sintered $\mathrm{Cu}$ nanoparticles are largely sintered together, as shown in Fig. 3. Therefore, a much larger number of micro- and nano-scale menisci can be offered by the $\mathrm{Al}_{2} \mathrm{O}_{3}$ nanoparticles. With much more area available for thin-film evaporation, the $R_{\mathrm{e}, \min }$ for the case with 0.01 $\mathrm{g} \mathrm{Al}_{2} \mathrm{O}_{3}$ nanoparticles appears lower than the sintered $\mathrm{Cu}$-nanoparticle case. With $0.04 \mathrm{~g} \mathrm{Al}_{2} \mathrm{O}_{3}$ nanoparticles, the $R_{\mathrm{e}, \min }$ is about the same as that with $0.01 \mathrm{~g} \mathrm{Al}_{2} \mathrm{O}_{3}$ nanoparticles. Comparing Figs. $7 \mathrm{~b}$ and $7 \mathrm{c}$, we can see that the upper mesh layer is covered with nanoparticles for the $0.04 \mathrm{~g}$ case. It is likely that the particle densities near the bottom are similar in the two cases. The $R_{\mathrm{e}, \min } \mathrm{S}$ are therefore similar. As to the $Q_{\max }$ of these two cases, the increase is $6 \%$ and $20 \%$, respectively, in comparison with the case without nanoparticles. In spite of the $\pm 8 \%$ uncertainty in the present experiments, the increasing trend in $Q_{\max }$ with increased amount of $\mathrm{Al}_{2} \mathrm{O}_{3}$ nanoparticles reliably indicates the stronger effect at a larger nanoparticle loading. The reasons for improved $Q_{\max }$ may be related to the enhanced capillarity offered by the nanoparticle agglomerates (Do et al., 2010).

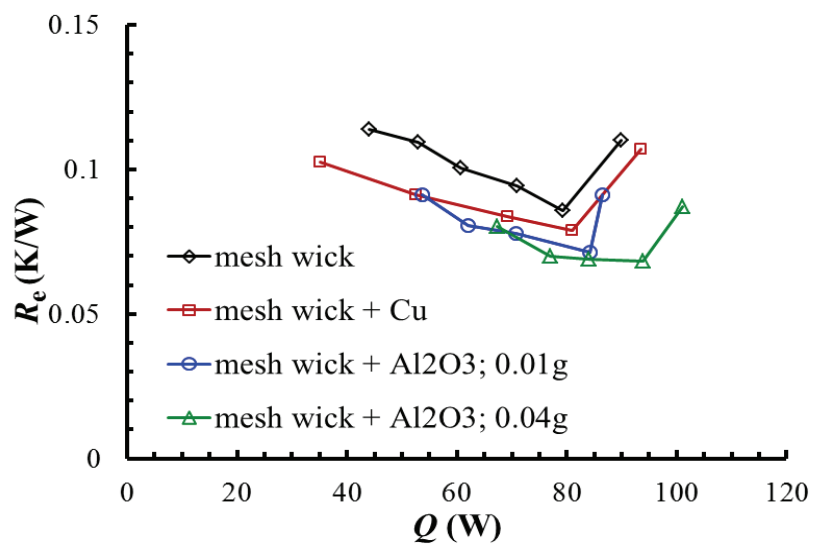

Fig. 8 Evaporator resistances $R_{\mathrm{e}}$ versus heat load $Q$ for various working fluids, $v=0.8 \mathrm{~cm}^{3}$.

\section{CONCLUSIONS}

Visualization experiments have been conducted to investigate the evaporation characteristics in the nanoparticle-laden mesh-wick evaporator of heat pipe with water as the working fluid. In one case, an amount of $0.01 \mathrm{~g} \mathrm{Cu}$ nanoparticles is sintered in the evaporator; in two other cases, $0.8 \mathrm{~g}$ nanofluid respectively containing $0.01 \mathrm{~g}(0.31 \mathrm{vol} \%)$ or $0.04 \mathrm{~g}(1.25 \mathrm{vol} \%) \mathrm{Al}_{2} \mathrm{O}_{3}$ nanoparticles is filled into the heat pipe. The tests are conducted as the $\mathrm{Al}_{2} \mathrm{O}_{3}$ nanoparticles have sedimented. The following conclusions are reached:

1. The evaporation process of nanoparticle-laden mesh wicks is similar to that of mesh wicks without nanoparticles. With increasing heat load, the liquid layer gradually recedes and the evaporator resistance decreases to a minimum value before a rise in response to the occurrence of local dryout in the evaporator. In all the test cases, the evaporator appears quiescent with no nucleate boiling observed.

2. The minimum evaporator resistances are slightly improved in the case with $0.01 \mathrm{~g}$ sintered $\mathrm{Cu}$ nanoparticles. Stronger improvements are obtained in the minimum evaporator resistance with $0.01 \mathrm{~g}$ or $0.04 \mathrm{~g}$ sedimented $\mathrm{Al}_{2} \mathrm{O}_{3}$ nanoparticles. In the latter case, the minimum evaporator resistance is reduced by about $20 \%$. This may be because the nanoparticles provide additional heat paths with a large number of micro- and nano-scale menisci for thin-film evaporation.

3. The maximum heat load is slightly increased in the case with $0.01 \mathrm{~g}$ sintered $\mathrm{Cu}$ nanoparticles. The increases are more significant in the cases with $0.01 \mathrm{~g}$ or $0.04 \mathrm{~g} \mathrm{Al}_{2} \mathrm{O}_{3}$ nanoparticles. In the latter case the increase reaches about
$20 \%$. This may result from the enhanced capillarity offered by the nanoparticle agglomerates in the evaporator.

\section{ACKNOWLEDGEMENTS}

This work was financially supported by National Science Council, ROC under Contract NSC101-2221-E-007-058.

\section{NOMENCLATURE}

$\begin{array}{ll}A_{\mathrm{e}} & \text { heated area }\left(\mathrm{cm}^{2}\right) \\ q & \text { heat flux }\left(\mathrm{W} / \mathrm{cm}^{2}\right) \\ Q & \text { heat flow }(\mathrm{W}) \\ R_{\mathrm{e}} & \text { evaporator resistance }(\mathrm{K} / \mathrm{W}) \\ v & \text { liquid charge }\left(\mathrm{cm}^{3}\right) \\ \mathrm{T} & \text { thermocouple }\end{array}$

$\begin{array}{ll}\text { Subscripts } & \\ \text { cond } & \text { lateral conduction } \\ \mathrm{e} & \text { evaporator } \\ \max & \text { maximum } \\ \min & \text { minimum } \\ \mathrm{t} & \text { total }\end{array}$

\section{REFERENCES}

Asirvatham, L.G., Nimmagadda, R., and Wongwises, S., 2013, "Heat Transfer Performance of Screen Mesh Wick Heat Pipes Using SilverWater Nanofluid," International Journal of Heat and Mass Transfe, 60, 201-209.

http://dx.doi.org/10.1016/j.ijheatmasstransfer.2012.11.037

Do, K.H., Ha, H.J., and Jang, S.P., 2010, "Thermal Resistance of Screen Mesh Wick Heat Pipes Using the Water-Based $\mathrm{Al}_{2} \mathrm{O}_{3}$ Nanofluids," International Journal of Heat and Mass Transfer, 53, 5888-5894

http://dx.doi.org/10.1016/j.ijheatmasstransfer.2010.07.050

Kang, S.W., Wei, W.C., Tsai, S.H., and Yang, S.Y., 2006, "Experimental Investigation of Silver Nanofluid on Heat Pipe Thermal Performance," Applied Thermal Engineering, 26, 2377-2382.

http://dx.doi.org/10.1016/j.applthermaleng.2006.02.020

Kang, S.-W., Wei, W.-C., Tsai, S.-H., and Huang, C.-C., 2009, "Experimental Investigation of Nanofluids on Sintered Heat Pipe Thermal Performance," Applied Thermal Engineering, 29, 973-979. http://dx.doi.org/10.1016/j.applthermaleng.2008.05.010

Keblinski, P., Phillpot, S.R., Choi, S.U.S., and Eastman, J.A., 2002, "Mechanisms of Heat Flow in Suspensions of Nano-Sized Particles (Nanofluids)," International Journal of Heat and Mass Transfer, Vol. 45 , pp. $855-863$.

http://dx.doi.org/10.1016/S0017-9310(01)00175-2

Kole, M. and Dey, T.K., 2013, "Thermal Performance of Screen Mesh Wick Heat Pipes Using Water-Based Copper Nanofluids," Applied Thermal Engineering, 50, 763-770.

http://dx.doi.org/10.1016/j.applthermaleng.2012.06.049

Kumaresan G., Venkatachalapathy, S., 2012, "A Review on Heat Transfer Enhancement Studies of Heat Pipes Using Nanofluids," Frontiers in Heat Pipes, 3, 043001.

http://dx.doi.org/10.5098/fhp.v3.4.3001

Kwark, S.M., Kumar, R., Moreno, G., Yoo, J., and You, S.M., 2010, "Pool Boiling Characteristics of Low Concentration Nanofluids," International Journal of Heat and Mass Transfer, 53, 972-981. 
http://dx.doi.org/10.1016/j.ijheatmasstransfer.2009.11.018

Lin, Y.H., Kang, S.W., and Chen, H.L., 2008, "Effect of Silver Nanofluids on Pulsating Heat Pipe Thermal Performance," Applied Thermal Engineering, 28, 1312-1317.

http://dx.doi.org/10.1016/j.applthermaleng.2007.10.019

Liou, J.-H., Chang, C.-W., Chao, C., and Wong, S.-C., 2010, "Visualization and Thermal Resistance Measurement for the Sintered Mesh-Wick Evaporator in Operating Flat-Plate Heat Pipes," International Journal of Heat and Mass Transfer, 53, 1498-1506.

http://dx.doi.org/10.1016/j.ijheatmasstransfer.2009.11.046

Liu, Z.H., Xiong, J.G., and Bao, R., 2007, "Boiling Heat Transfer Characteristics of Nanofluids in a Flat Heat Pipe Evaporator with Micro-Grooved Heating Surface," International Journal of Multiphase Flow, 33, 1284-1295.

http://dx.doi.org/10.1016/j.ijmultiphaseflow.2007.06.009

Liu, Z.H., and Lu, L., 2009, "Thermal Performance of an Axially Microgrooved Heat Pipe Using Carbon Nanotube Suspensions," Journal of Thermophysics and Heat Transfer, 23, 170-175.

http://dx.doi.org/10.2514/1.38190

Liu, Z.H., and Zhu, Q.Z., 2011, “Application of Aqueous Nanofluids in a Horizontal Mesh Heat Pipe," Energy Conversion and Management, 52, 292-300.

http://dx.doi.org/10.1016/j.enconman.2010.07.001

Liu, Z.-H., Li, Y.-Y., 2012, “A New Frontier of Nanofluid Research Application of Nanofluids in Heat Pipes," International Journal of Heat and Mass Transfer, 55, 6786-6797.

http://dx.doi.org/10.1016/j.ijheatmasstransfer.2012.06.086

Ma, H.B., Wilson, C., Park, K., Choi, S.U.S., and Tirumala, T., 2006, "An Experimental Investigation of Heat Transport Capability in a Nanofluids Oscillating Heat Pipe," ASME Journal of Heat Transfer, 128, 1213-1216.

http://dx.doi.org/10.1115/1.2352789
Putra, N., Septiadi, W.N., Rahman, H., and Irwansyah, R., 2012, "Thermal Performance of Screen Mesh Wick Heat Pipes with Nanofluids," Experimental Thermal and Fluid Science, 40, 10-17. http://dx.doi.org/10.1016/j.expthermflusci.2012.01.007

Sureshkumar, R., Mohideen, S.T., Nethaji, N., 2013, "Heat Transfer Characteristics of Nanofluids in Heat Pipes: A Review," Renewable Sustainable Energy Review, 20, 397-410. http://dx.doi.org/10.1016/j.rser.2012.11.044

Tsai, C.Y., Chien, H.T., Ding, P.P., Chan, B., Luh, T.Y., and Chen, P.H., 2004, Effect of Structural Character of Gold Nanoparticles in Nanofluid on Heat Pipe Thermal Performance, Materials Letters, 58, 1461-1465.

http://dx.doi.org/10.1016/j.matlet.2003.10.009

Wang, G.-S., Song, B., Liu, Z.-H., 2010, “Operation Characteristics of Cylindrical Miniature Grooved Heat Pipe Using Aqueous $\mathrm{CuO}$ Nanofluids," Experimental Thermal Fluid Science, 34, 1415-1421. http://dx.doi.org/10.1016/j.expthermflusci.2010.07.004

Wong, S.-C., Liou, J.-H., and Chang, C.-W., 2010, "Evaporation Resistance Measurement and Visualization for Sintered Copper-Powder Evaporator in Operating Flat-Plate Heat Pipes," International Journal of Heat and Mass Transfer, 53, 3792-3798.

http://dx.doi.org/10.1016/j.ijheatmasstransfer.2010.04.031

Wong, S.-C., Lin, Y.-C., and Liou, J.-H., 2012, "Visualization and Evaporation Resistance Measurement in Heat Pipes Charged with Water, Methanol or Acetone," International Journal of Thermal Sciences, 52, 154-160.

http://dx.doi.org/10.1016/j.ijthermalsci.2011.09.020

Yang, X.F., Liu, Z.H., and Zhao, J., 2008, "Heat Transfer Performance of a Horizontal Microgrooved Heat Pipe Using CuO Nanofluids," Journal of Micromechanics and Microengineering, 18, 035038. http://dx.doi.org/10.1088/0960-1317/18/3/035038 